\title{
Frequency and clinical relevance of anti-Mi-2 autoantibody in adult Brazilian patients with dermatomyositis
}

\author{
Maria Isabel Cardoso dos Passos Carvalho ${ }^{1}$ and Samuel Katsuyuki Shinjo ${ }^{1,2^{*}}$
}

\begin{abstract}
Background: To analyze the frequency and clinical relevance of anti-Mi-2 autoantibody in a representative sample of patients with dermatomyositis.

Methods: This longitudinal inception cohort study, from 2001 to 2017, included 87 definite adult dermatomyositis. Anti-Mi-2 analysis was performed using a commercial kit.

Results: Seventeen patients (19.5\%) had anti-Mi-2 and 70 (80.5\%) did not have this autoantibody. The following parameters were equally distributed between the patients with versus without anti-Mi-2: mean age at the disease diagnosis onset, median follow-up time, constitutional symptoms (baseline), cutaneous cumulative lesions, dysphagia, joint and pulmonary involvement. There was also no difference between the groups in relation to follow-up time, disease relapsing, treatment, disease status, deaths and occurrence of neoplasia. In contrast, patients with anti-Mi2 antibodies had higher frequency of elevated serum levels of muscle enzymes at disease onset (median: creatine phosphokinase 6240 [3800-9148] U/L and aldolase 60.0 [35.0-138.0] U/L), lower frequency of pulmonary involvement at disease onset (5.9\%), less current glucocorticoid dose (median: 0 [0-10] mg/day), and higher frequency of disease remission during follow-up (58.8\%) in comparison with patients without anti-Mi-2 autoantibody (484 [115-4880] and 12.1 [6.3-70.0] U/L, 40.0\%, 0 [0-10] mg/day, 27.1\%, respectively).

Conclusion: The anti-Mi-2 autoantibody was found in one fifth of patients with dermatomyositis. This autoantibody was associated with a lower occurrence of pulmonary involvement, a higher frequency of disease in remission, and elevated levels of muscle enzymes. There was also no correlation regarding the frequency of disease relapsing or neoplasia development.
\end{abstract}

Keywords: Autoantibodies, Dermatomyositis, myositis, Remission

\section{Introduction}

Dermatomyositis (DM) is a systemic autoimmune myopathy that primarily affects the skin and skeletal striated muscle [1-5]. Concerning cutaneous, heliotrope rash and Gottron's papules are classic lesions. However, other skin involvements may occur, such as a "V"-neck sign, "shawl" sign, "mechanic's hands", facial rash, cuticular hypertrophy, periungual hyperemia, vasculitis, ulcers, calcinosis, among others [1-14].

\footnotetext{
* Correspondence: samuel.shinjo@gmail.com

${ }^{1}$ Division of Rheumatology, Faculdade de Medicina FMUSP, Universidade de Sao Paulo, Sao Paulo, Brazil

${ }^{2}$ Disciplina de Reumatologia, Faculdade de Medicina, Universidade de Sao Paulo, Av. Dr. Arnaldo, 455, $3^{\circ}$ andar, sala 3150 - Cerqueira César, Sao Paulo CEP: 01246-903, Brazil
}

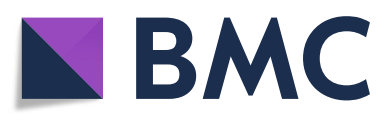

(c) The Author(s). 2019 Open Access This article is distributed under the terms of the Creative Commons Attribution 4.0 International License (http://creativecommons.org/licenses/by/4.0/), which permits unrestricted use, distribution, and reproduction in any medium, provided you give appropriate credit to the original author(s) and the source, provide a link to the Creative Commons license, and indicate if changes were made. The Creative Commons Public Domain Dedication waiver (http://creativecommons.org/publicdomain/zero/1.0/) applies to the data made available in this article, unless otherwise stated. which can be classified into myositis-specific or associated [2, 7-18]. Among the myositis-specific autoantibodies, although there are controversies in the literature, anti-Mi-2 autoantibody has been correlated with the presence of cutaneous lesions [2, 7, 9-14], absence of pulmonary fibrosis $[7,9,10,13,15]$, low risk of malignancy $[7,9,13-15]$ and good disease outcome with glucocorticoid treatment $[9,13,15]$. However, these studies were not only based on patients with DM but also on other inflammatory myopathies, which made it difficult to make precise conclusions about the reactivity of anti-Mi-2 autoantibody in patients with DM.

Anti-Mi-2 autoantibody has been found in 2 to $45 \%$ of adult DM patients [7-17]. This enormous variability 
occurs due to scarcity of studies and different techniques used for this autoantibody identification, coupled with a large variability and relatively small samples [7-18]. Furthermore, few studies have evaluated the follow-up and disease relapsing frequency of DM patients with antiMi-2 autoantibody $[9,10,13,15,18]$.

Therefore, the aims of the present study were: a) to evaluate the prevalence and reactivity of anti-Mi-2 autoantibody in a retrospective cohort study with a representative sample of Brazilian patients with DM; b) to evaluate the possible associations between anti-Mi-2 autoantibodies and disease features, relapses, therapy and outcomes of these patients with DM.

\section{Subject and methods}

A retrospective cohort, single-center study evaluating the presence of anti-Mi-2 autoantibody in adult patients with definite DM, according to the 2017 European League Against Rheumatism / American College of Rheumatology (EULAR / ACR) criteria classification [19], was conducted. All patients evaluated were recruited from our tertiary service between 2001 and 2017.

Exclusion criteria included the presence of associated systemic autoimmune diseases (overlap's syndrome), neoplasia (previous or concomitant to DM onset), pulmonary infections (i.e., tuberculosis), chronic obstructive pulmonary disease, history of chronic smoking, clinically amyopathic DM, a positivity to antisynthetase (anti-Jo-1, PL-7, PL-12, OJ or EJ), anti-MDA-5, anti-PM/Scl or anti-Ku autoantibodies. Moreover, patients without collected serum/plasma were also excluded. Thus, a total of 87 patients were analyzed from the present study.

The following data on eligible patients were evaluated from electronic medical records, with pre-standardized and parameterized information:

A) Information referring to the initial diagnostic investigation:

- Demographics: age at disease diagnosis, time between diagnosis and symptoms onset, gender and ethnicity

- Clinical manifestations: constitutional symptoms (fever and weight loss, at baseline), heliotrope rash, Gottron's papules / sign, facial rash, "V-neck" sign, "shawl" sign, periungual hyperemia, vasculitis, calcinosis, ulcers, Raynaud's phenomenon, muscle weakness of upper and lower limbs according to the Medical Research Council [20], dysphagia and pulmonary (dyspnea: moderate to low effort), and joint involvement (arthralgia or nonerosive arthritis)

- Changes on high-resolution computer tomography images of the lung: incipient interstitial lung disease (ILD), "ground glass" (opacity) and pulmonary fibrosis in both lung bases

- Serum levels of muscle enzymes in blood samples: creatine phosphokinase (reference value: 32-294

$\mathrm{U} / \mathrm{L}$ ) and aldolase (reference value: 1.0-7.5 U/L).

B) Information referring to the patients' last follow-up:

- Disease relapsing: which was defined as clinical relapse (i.e., muscle and/or dermatological manifestations) and/or biochemical relapses (i.e., increase of serum muscle enzymes for which there was no other explanation)

- Neoplasia

- Death.

C) Information referring to last medical consultation:

- Clinical remission: was considered when continuous 6-month period of no evidence of disease activity while not receiving myositis therapy, and complete clinical response: was defined as the continuous 6-month period of no evidence of disease activity while still receiving myositis therapy

- Treatment (i.e., glucocorticoid, immunosuppressive or immunomodulatory drugs).

\section{Autoantibody analysis}

Serum samples stored at $-20^{\circ} \mathrm{C}$ were collected at the time of the initial investigation of active disease (clinical and laboratory parameters). Identification of anti-Mi-2 as well as Jo-1, PL-7, PL-12, OJ, EJ, Ku and PM/Scl autoantibodies were performed using a commercial kit (Myositis Profile 3, Euroimmun, Germany) according to the manufacturer's protocol. The evaluation of the results was based on the established method in a previous study [7]. Anti-MDA-5 autoantibody identification was performed by the Enzyme-Linked Immunosorbent Assay (ELISA) method, through recombinant MDA-5 and the anti-MDA-5 monoclonal antibody (MyBioSource, CA, USA). Results were evaluated according to an established method in a previous study [21].

\section{Statistical analysis}

The Kolmogorov-Smirnov test was used to evaluate the distribution of each of the continuous variables. The results were expressed as mean \pm standard deviation for continuous variables and as numbers (\%) for categorical variables. Median values (25th - 75th interquartile range) were calculated for continuous variables that were nonnormally distributed. Comparisons between the patients with vs. without anti-Mi-2 were made using Student's ttest or the Mann-Whitney test for continuous variables, whereas the chi-squared test or the Fisher's exact test was used to evaluate the categorical variables. The Odds ratio (OR) and $95 \%$ confidence interval $(95 \% \mathrm{CI})$ of percentage were calculated by a binomial distribution. 
Logistic regression was carried out to evaluate association of anti-Mi- 2 and covariates that were statistically significant based on the univariate analysis. $P<0.05$ was considered to indicate statistical significance. All of the analyses were performed using the SPSS 15.0 statistics software (Chicago, USA).

\section{Availability of data and materials}

Please contact author for data requests.

\section{Results}

The general feature comparisons between patients with $(n=17)$ versus without $(n=70)$ anti-Mi-2 autoantibody were showed in the Table 1.

Mean age at diagnosis was 42.4 years, with a predominance of females (73.6\%) and white ethnicity (79.3\%). Median disease duration and total follow up time were 4.3 years. The distribution of these data was also comparable between patients with vs. without anti-Mi-2 autoantibody.

Constitutional symptoms at baseline occurred in $59.8 \%$ of the patients. Regarding the cumulative cutaneous manifestations, 96.6 and $90.8 \%$ of the DM patients had Gottron's papules / signal and heliotrope rash, respectively. Facial rash was present in $66.7 \%$ of the cases, followed by Raynaud's phenomenon (46.0\%), "V-neck" sign (44.8\%), "shawl" sign (24.1\%), vasculitis (21.8\%), ulcers $(14.9 \%)$ and calcinosis (3.4\%). Dysphagia and articular involvement were found in 49.4 and $35.6 \%$ of the cases, respectively. All these parameters were equally distributed between patients with vs. without anti-Mi-2 autoantibody (Table 1).

Concerning pulmonary involvement, dyspnea and incipient ILD occurred in 33.3 and $29.9 \%$, respectively, but in significantly lower frequency in patients with anti-Mi-2, when compared to those without this autoantibody.

Table 1 General features of patients with dermatomyositis

\begin{tabular}{|c|c|c|c|c|}
\hline & $\begin{array}{l}\text { Total } \\
(n=87)\end{array}$ & $\begin{array}{l}\mathrm{Mi}-2(+) \\
(n=17)\end{array}$ & $\begin{array}{l}\mathrm{Mi}-2(-) \\
(n=70)\end{array}$ & $P$ value \\
\hline Age at disease diagnosis (years) & $42.4 \pm 13.8$ & $43.1 \pm 13.7$ & $42.3 \pm 14.0$ & 0.819 \\
\hline Gender: female & 64 (73.6) & $13(76.5)$ & $41(72.9)$ & 1.000 \\
\hline Ethnicity: white & $69(79.3)$ & $15(88.2)$ & $44(77.1)$ & 0.696 \\
\hline Disease duration (years) & $4.3[2.9-7.1]$ & $4.5[3.0-6.0]$ & $4.3[2.5-7.5]$ & 0.945 \\
\hline Duration of follow-up time (years) & $4.3[2.9-7.1]$ & $4.5[3.0-6.0]$ & $4.3[2.5-7.5]$ & 0.945 \\
\hline Constitutional symptoms (baseline) & $52(59.8)$ & $11(64.7)$ & 41 (58.6) & 0.786 \\
\hline \multicolumn{5}{|l|}{ Cumulative manifestations } \\
\hline \multicolumn{5}{|l|}{ Cutaneous manifestations } \\
\hline Gottron's papules/sign & $84(96.6)$ & $17(100.0)$ & $67(95.7)$ & 1.000 \\
\hline Heliotrope rash & 79 (90.8) & $15(88.2)$ & $64(91.4)$ & 0.651 \\
\hline Facial rash & $58(66.7)$ & $14(82.4)$ & $44(62.9)$ & 0.247 \\
\hline Raynaud's phenomenon & $40(46.0)$ & $10(58.8)$ & $30(42.9)$ & 0.294 \\
\hline "V-neck" sign & $39(44.8)$ & $9(52.9)$ & $30(42.9)$ & 0.412 \\
\hline "Shawl" sign & $21(24.1)$ & $5(29.4)$ & $16(22.9)$ & 0.752 \\
\hline Vasculitis & $19(21.8)$ & $1(5.9)$ & $18(25.7)$ & 0.103 \\
\hline Ulcers & $13(14.9)$ & $3(17.6)$ & $10(14.3)$ & 0.715 \\
\hline Calcinosis & $3(3.4)$ & 0 & $3(4.3)$ & - \\
\hline Dysphagia & $43(49.4)$ & $11(64.7)$ & $32(45.7)$ & 0.279 \\
\hline Articular involvement & 31 (35.6) & $3(17.6)$ & $28(40.0)$ & 0.094 \\
\hline Pulmonary involvement & $31(35.6)$ & $1(5.9)$ & $30(42.9)$ & 0.004 \\
\hline Dyspnea & $29(33.3)$ & $1(5.9)$ & $28(40.0)$ & 0.008 \\
\hline Incipient interstitial lung disease & $26(29.9)$ & $1(5.9)$ & $25(35.7)$ & 0.017 \\
\hline Pulmonary fibrosis & $7(8.0)$ & 0 & $7(10.0)$ & - \\
\hline "Ground glass" & $11(12.6)$ & 0 & $11(15.7)$ & - \\
\hline Pneumomediastinum & $2(2.3)$ & 0 & $2(2.9)$ & - \\
\hline Creatine phosphokinase $(\mathrm{U} / \mathrm{L})$ & $992[148-8040]$ & 6240 [3800-9148] & $484[115-4880]$ & 0.001 \\
\hline Aldolase (U/L) & $18.5[6.6-60.7]$ & $60.0[35.0-138.0]$ & $12.1[6.3-40.0]$ & 0.002 \\
\hline
\end{tabular}


"Ground glass" seen in computed tomography, pneumomediastinum and pulmonary fibrosis occurred only in patients without anti-Mi-2 antibody.

Patients with anti-Mi-2 autoantibody had significantly higher serum levels of creatine phosphokinase and aldolase than those without anti-Mi-2 autoantibody.

Table 2 shows the treatment, disease relapsing, disease status, deaths, occurrence of neoplasia and follow-up of patients with DM. Concerning treatment, the patients with vs. without anti-Mi-2 autoantibody received the same frequency of methylprednisolone pulse therapy, intravenous human immunoglobulin and rituximab. In addition, both groups were using prednisone and/or immunosuppressive drugs for more than 6 months. However, the patients without anti-Mi- 2 autoantibody were using a higher median dose of the current prednisone when compared to those with anti-Mi-2 autoantibody.

There was also no significant difference in the frequency of disease relapsing, deaths and development of neoplasia between patients with vs. without anti-Mi-2 autoantibody. Regarding disease status, the frequency of remission was higher in patients with anti-Mi-2 autoantibody, whereas the frequency of those with complete clinical response and disease activity held a comparable distribution in both groups.

Univariate and multivariate analysis of parameters associated to anti-Mi-2 autoantibodies are shown in the Table 3. Disease remission, dyspnea and ILD were strongly associated to anti-Mi-2 autoantibodies only in univariate analysis.

\section{Discussion}

In the present study, the presence of the anti-Mi- 2 autoantibody was observed in $19.5 \%$ of DM patients. These patients with anti-Mi-2 autoantibody had a lower frequency of pulmonary involvement and reached a higher frequency of disease in remission compared to those without anti-Mi-2 autoantibody. In addition, patients with anti-Mi-2 autoantibody had a higher serum level of muscle enzymes at the onset of the disease. There was no significant difference in the distribution of neoplasia and disease relapsing between these groups.

Differently from the available literature [7-18], the present study evaluated the presence of anti-Mi-2 autoantibody in a homogeneous and representative sample of patients with DM. Although it was considered a rare disease, and despite the strict exclusion criteria, 87 consecutive patients with definite DM were included.

Although this was a retrospective cohort study, the data were obtained from electronic medical records with pre-standardized and parameterized information, allowing reliability in the results obtained. In addition, the patients participated in an average follow-up period of 4.3 years and came from a single center, which allows for greater homogeneity regarding the evaluation and therapeutic behaviors in the selected patients.

In the present study, the typical association between the presence of anti-Mi-2 autoantibody and the cutaneous lesions of DM was not seen. This may be justified by the fact that only patients with DM and, therefore, a

Table 2 Treatment, relapsing, disease status, death neoplasia and follow up of patients with dermatomyositis

\begin{tabular}{|c|c|c|c|c|}
\hline & $\begin{array}{l}\text { Total } \\
(n=87)\end{array}$ & $\begin{array}{l}\text { Mi-2 (+) } \\
(n=17)\end{array}$ & $\begin{array}{l}\mathrm{Mi}-2(-) \\
(n=70)\end{array}$ & $P$ value \\
\hline \multicolumn{5}{|l|}{ Treatment } \\
\hline Methylprednisolone pulse therapy & $37(42.5)$ & $10(58.8)$ & 27 (38.6) & 0.173 \\
\hline IVIG pulse therapy & $24(27.6)$ & $7(41.2)$ & $17(24.3)$ & 0.225 \\
\hline Rituximab & $15(17.2)$ & $4(23.5)$ & $11(15.7)$ & 1.000 \\
\hline \multicolumn{5}{|l|}{ Prednisone } \\
\hline Current use & $27(31.0)$ & $2(11.8)$ & $25(35.7)$ & 0.079 \\
\hline Current dose (mg/day) & $0[0-5]$ & $0[0-0]$ & $0[0-10]$ & 0.042 \\
\hline \multicolumn{5}{|l|}{ Immunosuppressive drugs } \\
\hline Current use & $49(56.3)$ & $7(41.2)$ & $42(60.0)$ & 0.182 \\
\hline Disease relapsing & $17(19.5)$ & $3(17.6)$ & $14(20.0)$ & 1.000 \\
\hline \multicolumn{5}{|l|}{ Current disease status } \\
\hline Disease remission & $29(33.3)$ & $10(58.8)$ & $19(27.1)$ & 0.021 \\
\hline Complete clinical response & $49(56.3)$ & $6(35.3)$ & $43(61.4)$ & 0.062 \\
\hline Disease activity & $9(10.3)$ & $1(5.9)$ & $8(11.4)$ & 0.682 \\
\hline Death & $12(13.8)$ & $2(11.8)$ & $10(14.3)$ & 1.000 \\
\hline Neoplasia & $4(4.6)$ & $2(11.8)$ & $2(2.9)$ & 0.170 \\
\hline Follow-up & 38 (43.7) & $5(29.4)$ & $33(47.1)$ & 0.279 \\
\hline
\end{tabular}

IVIG Intravenous human immunoglobulin 
Table 3 Univariate and multivariate analysis of parameters associated to anti-Mi-2 autoantibodies

\begin{tabular}{|c|c|c|c|c|}
\hline & \multicolumn{2}{|c|}{ Univariate analysis } & \multicolumn{2}{|c|}{ Multivariate analysis } \\
\hline & $\mathrm{OR}$ & $95 \%$ IC & $\mathrm{OR}$ & $95 \%$ IC \\
\hline Current dose prednisone & 0.88 & $0.74-1.04$ & & \\
\hline Disease remission & 3.84 & $1.28-11.52$ & 2.47 & $0.78-7.81$ \\
\hline Creatine phosphokinase & 1.00 & $1.00-1.00$ & & \\
\hline Aldolase & 1.01 & $1.00-1.02$ & & \\
\hline Dyspnea & 0.10 & $0.01-0.73$ & 0.20 & $0.01-2.29$ \\
\hline Incipient interstitial lung disease & 0.12 & $0.01-0.88$ & 0.40 & $003-4.64$ \\
\hline
\end{tabular}

Cl Confidence interval, OR Odds ratio

high frequency of cutaneous lesions (for example: $96.6 \%$ Gottron's papules and $90.8 \%$ heliotrope rash) were included in the study.

Reinforcing the literature data $[7,9,10,13,15]$ the presence of anti-Mi-2 autoantibody was related to a lower frequency of pulmonary involvement (dyspnea and incipient ILD). In addition, there were no cases of pneumomediastinum, ground glass lesions and pulmonary fibrosis by computed tomography in patients with anti-Mi-2 autoantibody. These results are relevant because the possible factors that could interfere with the interpretation of the obtained data were excluded. In fact, they were excluded, for example, if they presented with other systemic autoimmune diseases, pulmonary infections, chronic obstructive pulmonary disease, a chronic history of smoking, clinically amyopathic DM, antisynthetase syndrome, presence of anti-MDA-5 autoantibodies, anti-PM/Scl or anti-Ku autoantibodies.

Patients with anti-Mi-2 autoantibody had high levels of muscle enzymes at the time of diagnosis of the disease, which reinforce the literature data [16]. The Mi-2 expression is up-regulated in human DM muscle tissue expressing markers of regeneration [22]. that also reflects in the possible elevated creatine phosphokinase levels. As a consequence, the Mi-2 expression could be associated to the presence of serum anti-Mi-2 autoantibody.

No difference was observed in the prevalence of disease relapsing during follow-up. In the literature $[7,9$, $10,13,15]$, the presence of anti-Mi-2 autoantibody has been related to a lower frequency of relapses.

Likewise, the association between the presence of antiMi-2 autoantibody and a lower incidence of neoplasia was not observed, unlike studies available in the literature $[7,9,13-15]$. However, only neoplasia developed after the diagnosis of DM was included, thus avoiding the inclusion of eventual patients with paraneoplastic syndrome. In addition, in order to evaluate a possible association between these autoantibodies and the development of neoplasia, as well as the frequency of deaths, a study with a longer follow-up period and with the inclusion of a larger sample will be necessary.

As to the course of the disease, the present study reinforces those of the literature $[7,9,10,13,15]$. Patients with anti-Mi-2 autoantibody had a higher frequency of disease in remission, and using less glucocorticoid than those without this autoantibody.

As a limitation of the present study, the inclusion of patients solely from a tertiary care center may not represent the full DM spectrum and could result in an overestimation of disease of a more severe disease.

\section{Conclusions}

The anti-Mi-2 autoantibody was observed in one fifth of patients with DM. The presence of this autoantibody correlated with a lower frequency of pulmonary involvement and a higher prevalence of disease in remission.

\section{Abbreviations}

Cl: Confidence interval; DM: Dermatomyositis; ELISA: Enzyme-Linked

Immunosorbent Assay; EULAR / ACR: European League Against Rheumatism / American College of Rheumatology; ILD: Interstitial lung diseases; OR: Odds ratio

\section{Acknowledgment}

Not applicable.

\section{Authors' contributions}

All authors contributed equally to write and review the manuscript. Both authors read and approved the final manuscript.

\section{Funding}

Federico Foundation; Faculdade de Medicina; Fundação de Amparo à

Pesquisa do Estado de São Paulo (FAPESP) (\#2011/12700-1) to SKS.

Availability of data and materials

Please contact author for data requests.

Ethics approval and consent to participate

This study was approved by the local Ethics Committee (HCFMUSP, CAPPesq, number 0114/11) and all participants signed the informed consent form.

\section{Consent for publication}

Not applicable.

\section{Competing interests}

The authors declare that they have no competing interests.

Received: 17 July 2018 Accepted: 25 June 2019

Published online: 02 July 2019

\section{References}

1. Bohan A, Peter JB. Polymyositis and dermatomyositis (second of two parts). N Engl J Med. 1975:292:403-7.

2. Dalakas MC. Inflammatory muscle diseases. N Engl J Med. 2015;372:1734-47. 
3. Dalakas MC. Review: an update on inflammatory and autoimmune myopathies. Neuropathol Appl Neurobiol. 2011;37:226-42.

4. Callen JP, Wortmann RL. Dermatomyositis. Clin Dermatol. 2006;24:363-73.

5. Koler RA, Montemarano A. Dermatomyositis. Am Fam Physician. 2001;64:1565-72.

6. Souza FH, Barros TB, Levy-Neto M, Shinjo SK. Adult dermatomyositis: experience of a Brazilian tertiary care center. Rev Bras Reumatol. 2012;37:264-7.

7. Cruellas MG, Viana V dos S, Levy-Neto M, Shinjo SK. Myositis-specific and myositis-associated autoantibody profiles and their clinical associations in a large series of patients with polymyositis and dermatomyositis. Clinics. 2013; 68:909-14.

8. Targoff IN, Reichlin M. The association between Mi-2 antibodies and dermatomyositis. Arthritis Rheum. 1985;28:796-803.

9. Love LA, Leff RL, Fraser DD, Targoff IN, Dalakas M, Plotz PH, et al. A new approach to the classification of idiopathic inflammatory myopathy: myositis-specific autoantibodies define useful homogeneous patient groups. Medicine. 1991;70:360-74.

10. Komura K, Fujimoto M, Matsushita T, Kaji K, Kondo M, Hirano T, et al. Prevalence and clinical characteristics of anti-Mi-2 antibodies in Japanese patient with dermatomyositis. J Dermatol Sci. 2005;40:215-7.

11. Ghirardello A, Zampieri S, Tarricone E, laccarino L, Bendo R, Briani C, et al. Clinical implications of autoantibody screening in patients with autoimmune myositis. Autoimmunity. 2006;39:217-21.

12. Ikeda N, Takahashi K, Yamaguchi Y, Inasaka M, Kuwana M, Ikezawa Z. Analysis of dermatomyositis-specific autoantibodies and clinical characteristics in Japanese patients. J Dermatol. 2011;38:973-9.

13. Hamaguchi Y, Kuwana M, Hoshino K, Hasegawa M, Kaji K, Matsushita T, et al. Clinical correlations with dermatomyositis-specific autoantibodies in adult Japanese patients with dermatomyositis: a multicenter cross-sectional study. Arch Dermatol. 2011;147:391-8.

14. Muro Y, Ishikawa A, Sugiura K, Akiyama M. Clinical features of anti-TIF1-a antibody-positive dermatomyositis patients are closely associated with coexistent dermatomyositis-specific autoantibodies and anti-TIF $1-\gamma$ or anti-Mi-2 autoantibodies. Rheumatology. 2012;51:1508-13.

15. Ghirardello A, Zampieri S, laccarino L, Tarricone E, Bendo R, Gambari PF, et al. Myositis autoantibodies and clinical phenotypes. Autoimmun Highlights. 2014;5:69-75.

16. Petri MH, Satoh M, Martin-Marquez BT, Vargas-Ramírez R, Jara LJ, Saavedra MA, et al. Implications in the difference of anti-Mi-2 and -p155/140 autoantibody prevalence in two dermatomyositis cohorts from Mexico City and Guadalajara. Arthritis Res Ther. 2013;15:R48.

17. Ghirardello A, Zampieri S, laccarino L, Tarricone E, Bendo R, Gambari PF, et al. Anti-Mi-2 antibodies. Autoimmunity. 2005;38:79-83.

18. Váncsa A, Gergely L, Ponyi A, Lakos G, Németh J, Szodoray P, et al. Myositisspecific and myositis-associated antibodies in overlap myositis in comparison to primary dermatopolymyositis: relevance for clinical classification: retrospective study of 169 patients. Joint Bone Spine. 2010;77:125-30.

19. Lundberg IE, Tjärnlund A, Bottai M, Werth VP, Pilkington C, de Visser M, International Myositis Classification Criteria Project Consortium, the Euromyositis Register, and the Juvenile Dermatomyositis Cohort Biomarker Study and Repository (UK and Ireland), et al. 2017 European league against rheumatism/American college of rheumatology classification criteria for adult and juvenile idiopathic inflammatory myopathies and their major subgroups. Arthritis Rheumatol. 2017;69:2271-82.

20. Medical Research Council. Aids to the examination of the peripheral nervous system, memorandum no. 45. London: Her Majesty's Stationery Office; 1981.

21. Borges IBP, Silva MG, Shinjo SK. Prevalence and reactivity of anti-melanoma differentiation associated gene-5 (anti-MDA-5) autoantibody in Brazilian patients with dermatomyositis. An Bras Dermatol. 2018;93:517-23.

22. Mammen AL, Casciola-Rosen LA, Hall JC, Christopher-Stine L, Corse AM, Rosen A. Expression of the dermatomyositis autoantigen Mi-2 in regenerating muscle. Arthritis Rheum. 2009;60:3784-93.

\section{Publisher's Note}

Springer Nature remains neutral with regard to jurisdictional claims in published maps and institutional affiliations.

Ready to submit your research? Choose BMC and benefit from:

- fast, convenient online submission

- thorough peer review by experienced researchers in your field

- rapid publication on acceptance

- support for research data, including large and complex data types

- gold Open Access which fosters wider collaboration and increased citations

- maximum visibility for your research: over $100 \mathrm{M}$ website views per year

At BMC, research is always in progress.

Learn more biomedcentral.com/submissions 